\title{
A note on a class of problems for a higher-order fully nonlinear equation under one-sided Nagumo-type condition
}

\author{
M.R. Grossinho ${ }^{\mathrm{a}, *}$, F. Minhós ${ }^{\mathrm{b}}$, A.I. Santos ${ }^{\mathrm{b}}$ \\ a Departamento de Matemática e Centro de Matemática e Aplicações à Previsão e Decisão Económica. Instituto Superior de Economia e Gestão. Technical \\ University of Lisbon. Rua do Quelhas, $n^{\circ}$ 6, 1200-781 Lisboa, Portugal \\ ${ }^{\mathrm{b}}$ Departamento de Matemática e Centro de Investigação em Matemática e Aplicações da U.E. (CIMA-UE). Universidade de Évora. R. Romão Ramalho, $n^{\circ}$ 59, \\ 7000-671 Évora, Portugal
}

\section{A R T I C L E I N F O}

\section{Article history:}

Received 15 October 2007

Accepted 28 August 2008

\section{MSC:}

34B10

$34 \mathrm{~B} 15$

$34 \mathrm{~L} 30$

\section{Keywords:}

Higher-order BVP

One-sided Nagumo-type conditions

Lower and upper solutions

A priori estimates

Leray-Schauder degree

\section{A B S T R A C T}

The purpose of this work is to establish existence and location results for the higher-order fully nonlinear differential equation

$$
u^{(n)}(t)=f\left(t, u(t), u^{\prime}(t), \ldots, u^{(n-1)}(t)\right), \quad n \geq 2,
$$

with the boundary conditions

$$
\begin{aligned}
& u^{(i)}(a)=A_{i}, \quad \text { for } i=0, \ldots, n-3, \\
& u^{(n-1)}(a)=B, \quad u^{(n-1)}(b)=C
\end{aligned}
$$

or

$$
\begin{aligned}
& u^{(i)}(a)=A_{i}, \quad \text { for } i=0, \ldots, n-3, \\
& c_{1} u^{(n-2)}(a)-c_{2} u^{(n-1)}(a)=B, \quad c_{3} u^{(n-2)}(b)+c_{4} u^{(n-1)}(b)=C,
\end{aligned}
$$

with $A_{i}, B, C \in \mathbb{R}$, for $i=0, \ldots, n-3$, and $c_{1}, c_{2}, c_{3}, c_{4}$ real positive constants.

It is assumed that $f:[a, b] \times \mathbb{R}^{n-1} \rightarrow \mathbb{R}$ is a continuous function satisfying onesided Nagumo-type conditions which allows an asymmetric unbounded behaviour on the nonlinearity. The arguments are based on the Leray-Schauder topological degree and lower and upper solutions method.

(c) 2008 Elsevier Ltd. All rights reserved.

\section{Introduction}

Let us consider the $n$ th-order differential equation

$$
u^{(n)}(t)=f\left(t, u(t), \ldots, u^{(n-1)}(t)\right),
$$

for $n \geq 2$, with the following boundary conditions

$$
\begin{aligned}
& u^{(i)}(a)=A_{i}, \\
& u^{(n-1)}(a)=B, \quad u^{(n-1)}(b)=C,
\end{aligned}
$$

\footnotetext{
* Corresponding author.

E-mail addresses: mrg@iseg.utl.pt (M.R. Grossinho), fminhos@dmat.uevora.pt (F. Minhós), aims@dmat.uevora.pt (A.I. Santos).
} 